\title{
Reproducibility of insulin sensitivity measured by the minimal model method
}

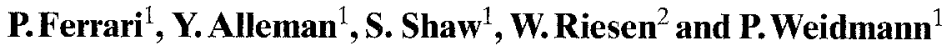 \\ ${ }^{1}$ Medizinische Poliklinik, University of Berne, and \\ ${ }^{2}$ Institute for Clinical Chemistry and Haematology, State Hospital, St. Gallen, Switzerland
}

Summary. Insulin resistance is a critical component underlying the altered glucose homeostasis in a variety of metabolic and non-metabolic disorders. Aging, body fat distribution, obesity, diabetes mellitus or hypertension are well recognized conditions associated with an impaired tissue sensitivity to insulin action. Apart from such constant factors, insulin sensitivity can be acutely modified by independent variables such as physical exercise, dietary factors, alcohol intake or harmless drugs. To evaluate the day-to-day intra-individual variation in insulin sensitivity, glucose homeostasis and lipid profiles, we investigated the insulin sensitivity index $\left(\mathrm{S}_{\mathrm{I}}\right)$ (determined by the minimal model method of Bergman), basal and post-glucose-load insulin and glucose levels, serum total triglyceride and lipoprotein cholesterol fractions in 15 healthy young men $(24 \pm 1$ year, mean \pm SEM), on two different occasions at an interval of 3 weeks (days 1 and 21), after 3 days of a standard dietary regimen and after an overnight fast. Blood pressure, heart rate, body weight and $24 \mathrm{~h}$ urinary sodium excretion were almost identical in the two phases. $\mathrm{S}_{\mathrm{I}(\text { day } 1)}$ varied from 4.2 to $15.8 \cdot 10^{-4} \cdot \mathrm{min}^{-1}$ pro $\mu \mathrm{U} / \mathrm{ml}$ (mean: $10.2 \pm 0.9)$ and correlated with $\mathrm{S}_{\mathrm{I}(\mathrm{day} 21)}(11.2 \pm 1.2$. $10^{-4} \cdot \mathrm{min}^{-1}$ pro $\left.\mu \mathrm{U} / \mathrm{ml}, r=0.78, p<0.0007\right)$. The slope of the relationship did not differ from $1(1.01, p>0.90)$, the intercept was close to the origin $(0.8, p>0.73)$ and the coefficient of variation was $14.4 \%$. Other variables of carbohydrate and lipid metabolism that were strongly correlated to each other on the two different days were: total serum lipids $(p<0.0009$ to 0.0002$)$ and the fasting and peak plasma insulin $(p<0.001$ to 0.0001$)$ and glucose levels $(p<0.005$ to 0.001$)$. These findings indicate that the assessment of in vivo insulin sensitivity using the minimal model method is practical and can be reproduced with accetable intra-individual variation in young healthy subjects.

Key words: Carbohydrate metabolism, insulin sensitivity, mathematical modelling, reproducibility.
Since the introduction of the first approach to measure insulin sensitivity in vivo by Himsworth in the 1930's [1,2], a number of other techniques for the evaluation of insulin sensitivity of the intact organism have emerged. However, the clinical assessment of insulin sensitivity has long been hindered by methodological limitations, and indeed a simple, sensitive and reproducible method for detecting slight endogenous or drug-related changes in insulin sensitivity in vivo is still lacking.

The "gold standard" for physiological studies so far has been the euglycaemic insulin clamp technique developed by Andres and De Fronzo [3-6]. This technique basically utilizes a constant insulin infusion to increase the glucose disappearance rate and a variable glucose infusion to maintain relatively constant plasma glucose levels [3-6]. The rate of glucose disposal is then a measure of the sensitivity of tissue to the action of insulin. Another method currently used is the insulin suppression test [6-8]. This protocol involves the inhibition of endogenous insulin se- cretion using either epinephrine and propranolol or somatostatin infusions. Exogenous insulin and glucose are infused concomitantly at constant rates, and the steadystate plasma glucose (SSPG) is considered a measure of the response to insulin resistance. A dynamic assessment of insulin sensitivity with mathematical (computer) modelling, termed the minimal model method, was developed by Bergman et al. in 1979 [6, 9-12]. The insulin and glucose data obtained from an intravenous glucose tolerance test can be implemented in a computer program, which is able to estimate a measure of insulin sensitivity. This method has been validated by comparative assessment with the euglycaemic insulin clamp technique [11, 12].

Regardless of the method used to measure insulin sensitivity, the latter is influenced by independent variables susceptible to daily variations such as the lipoprotein profile [13], dietary composition [14,15], physical activity [16] and drugs such as alcohol [17], aspirin [18] or nose drops containing adrenergic agonists [19]. Considering 
these confounding factors, it seems reasonable to argue that any measurement of insulin sensitivity could be liable to wide day-to-day intra-individual variations. So far few data have allowed only an indirect insight in the reproducibility of insulin sensitivity measurements $[15,20]$.

Therefore, considering the increasing interest in the pathogenic and therapeutic relevance of insulin resistance, the present study was designed to assess the intraindividual variation in insulin sensitivity index $\left(\mathrm{S}_{\mathrm{I}}\right)$ as measured with the minimal model method.

\section{Subjects and methods}

The study group consisted of 15 young ( $24 \pm 1$ year, mean $\pm S E M$ ) normotensive healthy male subjects. None had first degree relatives with diabetes mellitus. The body mass index in all volunteers was less than $25 \mathrm{~kg} / \mathrm{m}^{2}(21.9 \pm 0.5)$ and the waist/hip ratio was $0.85 \pm 0.02$. All subjects were non-diabetic volunteers in excellent physical and mental condition, and with a blood pressure consistently $<140 / 90 \mathrm{~mm} \mathrm{Hg}$; none was taking any drugs. Information on the family history of diabetes mellitus in parents and any siblings was obtained from the family doctors, the information was further validated by direct questioning of all parents. Insulin sensitivity and additional variables were assessed on two different days at a 3 -week interval (day 1 and 21), using a modified frequent sampling intravenous glucose tolerance test (FSIGT) [21].

The volunteers consumed a standard diet $[14,15]$, containing $2500 \mathrm{kcal}$ with $45 \%$ carbohydrates, $40 \%$ fat and $15 \%$ proteins during the 3 days prior to each study day. The salt intake was also standardized at $160 \mathrm{mmol}$ daily, and 24-h urine specimens were collected to monitor compliance. From one week preceding the first FSIGT procedure and during the entire duration of the study, alcohol ingestion was banned, and the subjects were instructed to maintain their usual physical activity. Caffeine and smoking were avoided for at least 3 days before the tests. The study was approved by the local ethical commitee and the subjects gave their written informed consent prior to the studies.

\section{Procedures}

The subjects entered the research unit at 07.00 hours after a 12-h overnight fast. They were asked to empty their bladders for completion of the 24-h urine collection, and body weight was recorded. Thereafter, the subjects assumed and maintained a supine position throughout the entire procedure. $S_{1}$ was assessed dynamically by the minimal model method $[9,12]$ with the use of the modified FSIGT [21]. Intravenous cannulas were placed in an antecubital vein of each arm. One was used for glucose and tolbutamide injection; blood was sampled from the needle in the contralateral arm, which was maintained patent with a slow saline infusion $(154 \mathrm{mmol} / \mathrm{l} \mathrm{NaCl}$, $1.0 \mathrm{ml} / \mathrm{min}$ ). After needle placement, $30 \mathrm{~min}$ of rest were allowed for reattainement of basal conditions. Basal samples were taken at -20 and $-10 \mathrm{~min}$; at 08.00 hours $(t=0)$ the modified FSIGT was begun with an injection of $50 \% \mathrm{D}$-glucose (300 $\mathrm{mg} / \mathrm{kg}$ body weight), administered smoothly over $60 \mathrm{~s}$ in an arm vein. At $t=20 \mathrm{~min}, 300 \mathrm{mg}$ tolbutamide (Orinase Diagnostic, Upjohn Co., Kalamazoo, Mich., USA) was injected in the same vein. Post-injection samples $(3 \mathrm{ml})$ were collected from the contralateral vein throughout $180 \mathrm{~min}$, according to the modified FSIGT protocol [21]. Sampling tubes contained $10 \mathrm{U}$ powdered heparin as anticoagulant and $2 \mathrm{mg} \mathrm{NaF}$ as glycolytic inhibitor; extreme care was taken to avoid contamination of the samples either with each other or with the saline. To achieve this, we used two adjacent stopcocks in the saline infusion.

Blood for determination of serum total lipids, lipoprotein fractions, plasma sodium, potassium and creatinine was collected at $\mathrm{t}=-20 \mathrm{~min}$.

\section{Analytical methods}

Insulin determinations from the two tests in one subject were always carried out in the same assay. Radioimmunoassay for measurement of plasma insulin was performed in duplicate, using Guinea pig antiporcine insulin antibody (Novo-BioLabs, Bagsvaerd, Denmark) and $\mathrm{I}^{125}$-porcine insulin as tracer in a working buffer consisting of $12.1 \mathrm{~g}$ Tris/ $\mathrm{HCl} \mathrm{pH} 7.4,0.2 \mathrm{~g}$ neomycin sulphate, $0.1 \mathrm{~g}$ sodium azide, $1 \mathrm{~g}$ EDTA and $0.3 \%$ bovine serum albumin. Plasma samples $(100 \mu \mathrm{l})$ were incubated overnight in a final volume of $600 \mu \mathrm{l}$ of working buffer containing antibody and tracer. Bound and free ligand were separated using dextran coated charcoal. Standard curves were constructed using canine insulin. Intra- and inter-assay coefficients of variation were $6.5 \%$ and $10.1 \%(n=30)$, respectively. Plasma glucose was measured in triplicate with a Technicon AAII autoanalyzer (Tarrytown, NY, USA) by the glucose oxidase technique. Intraassay coefficient of variation was $1.3 \%$. Serum total plasma cholesterol and triglycerides were measured by enzymatic methods (Boehringer-Mannheim, Mannheim, FRG). Lipoproteins were quantitated according to the Lipid Research Clinic recommendations [22]. Very-low-density lipoproteins (VLDL) were separated by ultracentrifugation (Airfuge, Beckman Instruments, Tarrytown, NY, USA). In the infranatant, cholesterol was measured (LDL + HDL) and LDL precipitated by phosphotungstate $\left(\mathrm{Mg}^{2+}\right)$ [23]. HDL-cholesterol was then measured in the supernatant. LDLcholesterol was calculated as the difference between these two measurements. The inter-assay coefficients of variation were $4.5 \%$ for LDL cholesterol and $3.5 \%$ for HDL cholesterol $(n=10)$.

\section{Data analysis and statistics}

The $S_{1}$ was calculated from FSIGT results using the program MINMOD (copyright R.N.Bergman, 1986). This program accepts as input the temporal pattern of plasma insulin during the modified FSIGT, and it must fit a simple (minimal) model of insulin-dependent glucose utilization to the measured glucose pattern. The model is the simplest mathematical representation that can account for the glucose dynamics during the modified FSIGT. The equations of the model are as follows [9]: $\mathrm{dG}(\mathrm{t}) / \mathrm{dt}=-\left[\mathrm{p}_{1}+\mathrm{X}(\mathrm{t})\right] \cdot \mathrm{G}(\mathrm{t})+\mathrm{p}_{1} \cdot \mathrm{G}_{\mathrm{b}}$, $d X(t) / d t=-p_{2} \cdot X(t)+p_{3} \cdot I(t)$, where $G(t)$ and $I(t)$ are the plasma glucose and insulin concentrations. $X(t)$ represents the time-dependent effect of the dynamic insulin response to accelerate glucose decline during the modified FSIGT. $G_{b}$ is the pre-injection glucose concentration. Parameters of the model are estimated from the least-squares fitting of the glucose data, and $S_{I}$ is calculated as the ratio of two of the fitted model parameters. This parameter is a measure of the effect of an increment in plasma insulin to enhance the fractional net disappearance of glucose from the extracellular compartment of glucose distribution.

\section{Statistical analysis}

Statistical analysis was performed with the help of the Statistical Analysis System software package (version 6.03, SAS Institute, Inc., Cary, NC, USA). Paired $t$-test was applied for comparison between two related samples throughout the study, and Pearson correlation analysis was used for assessment of relationships between variables.

\section{Results}

In these lean, normotensive and normolipidaemic male subjects, blood pressure $(130 / 76 \pm 3 / 2$ vs $125 / 76 \pm$ $3 / 3 \mathrm{mmHg}$, day 1 vs day 21$)$, heart rate $(62 \pm 2$ vs $59 \pm 4$ beats per min), body weight ( $69 \pm 2$ vs $69 \pm 2 \mathrm{~kg}$ ), plasma creatinine $(99 \pm 2$ vs $95 \pm 3 \mu \mathrm{mol} / \mathrm{l})$, sodium 


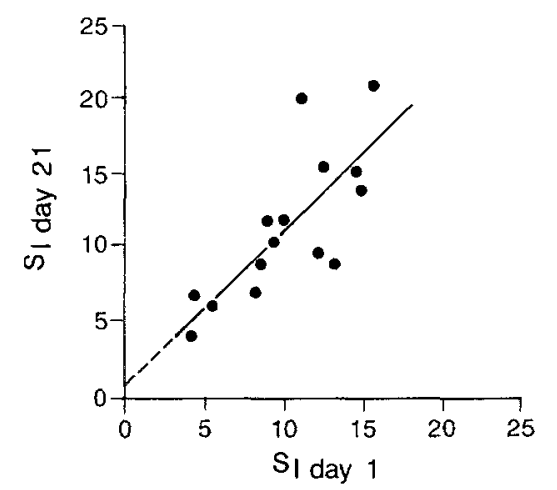

Fig. 1. Correlation between the insulin sensitivity indices $\left(\mathrm{S}_{\mathrm{I}}\left[10^{-4}\right.\right.$ $\left.\left.\times \min ^{-1} / \mu \mathrm{U} / \mathrm{ml}\right]\right)$ in 15 healthy young male subjects, derived from two frequent sampling intravenous glucose tolerance test procedures 3 weeks apart $(r=0.78, p<0.0007) . \mathrm{y}=1.01 \times+0.8$

(142 \pm 1 vs $141 \pm 1 \mathrm{mmol} / \mathrm{l}$ ), and potassium $(3.9 \pm 0.1$ vs $3.9 \pm 0.1 \mathrm{mmol} / \mathrm{l})$, as well as urinary sodium excretion ( $138 \pm 11$ vs $138 \pm 10 \mathrm{mmol} / 24 \mathrm{~h}$ ), were comparable on the two different occasions.

Mean fasting plasma insulin and glucose levels as well as the $S_{I}$ did not differ significantly between days 1 and 21 (Table 1, Fig.1). Mean $S_{\text {I(day 1) }}$ for all subjects averaged $10.2 \pm 0.9 \cdot 10^{-4} \cdot \mathrm{min}^{-1}$ pro $\mu \mathrm{U} / \mathrm{ml}$, individual values ranging from 4.2 to $15.8 \cdot 10^{-4} \cdot \mathrm{min}^{-1}$ pro $\mu \mathrm{U} / \mathrm{ml}$. $\mathrm{S}_{\mathrm{I}(\text { day } 1)}$ correlated $(r=0.78, p<0.0007)$ with $S_{\text {I(day } 21)}\left(11.2 \pm 1.2 \cdot 10^{-4}\right.$ $\cdot \mathrm{min}^{-1}$ pro $\mu \mathrm{U} / \mathrm{ml}$, range: $\left.4.0-20.8\right)$. The slope of the relationship did not differ from $1(1.01, p>0.90)$, the intercept was close to the origin $(0.8, p>0.73)$, and the coefficient of variation was $14.4 \%$.

Compared with day 1 , serum total triglycerides, total cholesterol, HDL-cholesterol and LDL-cholesterol were unchanged after the 21 days of observation (Table 1 ). Coefficients of correlations between values obtained on days 1 and 21, respectively ranged from $r=0.73$ for HDLcholesterol $(p<0.002)$ to $r=0.83$ for total triglycerides $(p<0.0002)$.

\section{Discussion}

These findings indicate that the assessment of insulin sensitivity in vivo using the minimal model method is practi$\mathrm{cal}$ and can be reproduced with only small intra-individual variations. In the 15 young men studied, the difference in $\mathrm{S}_{\mathrm{I}}$ averaged $8.9 \%$, and the mean coefficient of intra-individual variation was $14.4 \%$. Moreover, $\mathrm{S}_{\mathrm{I}}$ values at the two time points correlated closely $(r=0.78, p<0.0007)$, the slope of this relationship was not significantly different from 1.00 , and the intercept did not differ from 0 .

Utilising the euglycaemic insulin clamp technique, Pollare et al. reported in a group of 50 hypertensive patients a $17 \%$ difference between the mean insulin-sensitivity indices determined on two different occasions during placebo administration [20]. With application of the insulin suppression test, an $8.9 \%$ difference between the mean steady-state plasma glucose levels, assessed on two different occasions 10 days apart, was described in 19 nonobese subjects ingesting a diet containing $43 \%$ carbohy- drates [24]. Using the minimal model method, insulin sensitivity determined in eight healthy subjects on a normal and after 3 to 5 days of a very high carbohydrate intake (41 and $85 \%$ of total calories, respectively) was found to differ by $8.2 \%$ only [15]. However, none of these studies provided information on coefficients of variation and correlations between repeated determinations.

Apart from the well-known categorical variables, insulin sensitivity may be acutely impaired by several independent continuous variables which are liable to daily variations [13-19]. In the present study, metabolic testing was performed on a standard diet, and intake of alcohol or drugs was avoided. Pharmacological interactions are potentially important, since Shelmet an co-workers reported a $35 \%$ reduction in glucose disposal upon infusion of ethanol causing a steady-state blood alcohol level of $0.6 \mathrm{~g} / 1$ [17]; while administration of aspirin at a daily dosage of $3 \mathrm{~g}$ for 3 days decreased insulin sensitivity by about $28 \%$ [18]. Additional modifying factors, such as serum lipoprotein composition [13] or physical activity [16, 25, 26], were stable on the two study days.

Normal human subjects display a wide range of insulin sensitivity. This could not be explained by differences in age, weight, body fat distribution (waist-hip ratio) or blood pressure $[8,15,27-29]$, as their inter-individual variability in the present study group was minimal. Insulin mediated glucose disposal depends on complex receptor and post-receptor interactions $[30,31]$ as well as on tissue blood flow [32]. Moreover, physical activity may have an important influence, modifying insulin sensitivity over weeks rather than acutely $[16,25,26]$. In 10 middle-aged men, a weekly effort of 30 to 40 min of jogging over 9 weeks produced a $26 \%$ improvement in insulin sensitivity [16].

Furthermore, methodological aspects deserve consideration, including the acute stress reaction and room temperature during the investigative procedure. The influence of these factors is difficult to quantitate. Our subjects were studied in the same room at approximately

Table 1. Carbohydrate variables from frequent sampling intravenous glucose tolerance test procedures or base-line lipoprotein profiles and their correlations on two different study days in 15 normal male subjects. (Mean \pm SEM)

\begin{tabular}{lccll}
\hline & Day 1 & Day 21 & R-value & $p$ \\
\hline $\begin{array}{l}\text { Fasting plasma } \\
\text { glucose (mmol/l) }\end{array}$ & $4.88 \pm 0.10$ & $4.99 \pm 0.09$ & 0.71 & $<0.005$ \\
$\begin{array}{l}\text { Fasting plasma } \\
\text { insulin }(\mu \mathrm{U} / \mathrm{ml})\end{array}$ & $8.7 \pm 0.8$ & $9.2 \pm 0.8$ & 0.74 & $<0.001$ \\
$\begin{array}{l}\text { Insulin sensitivity } \\
\text { index }\left(10^{-4} \cdot \mathrm{min}^{-1}\right.\end{array}$ & & & & \\
$\left.\cdot \mu \mathrm{U}^{-1} \cdot \mathrm{ml}\right)$ & $10.2 \pm 0.9$ & $11.2 \pm 1.2$ & 0.78 & $<0.0007$ \\
$\begin{array}{l}\text { Peak plasma } \\
\text { glucose (mmol/l) }\end{array}$ & $13.1 \pm 0.5$ & $13.6 \pm 0.7$ & 0.64 & $<0.001$ \\
insulin $(\mu \mathrm{U} / \mathrm{ml})$ & $53 \pm 12$ & $59 \pm 16$ & 0.96 & $<0.0001$ \\
$\begin{array}{l}\text { Cholesterol } \\
\text { total }(\mathrm{mmol} / \mathrm{l})\end{array}$ & $4.2 \pm 0.1$ & $4.4 \pm 0.2$ & 0.76 & $<0.0009$ \\
$\begin{array}{l}\text { HDL }(\mathrm{mmol} / \mathrm{l}) \\
\text { LDL (mmol/1) }\end{array}$ & $1.2 \pm 0.07$ & $1.3 \pm 0.07$ & 0.73 & $<0.002$ \\
$\begin{array}{l}\text { Triglycerides total } \\
\text { (mmol/l) }\end{array}$ & $2.6 \pm 0.1$ & $2.6 \pm 0.2$ & 0.79 & $<0.0004$ \\
\hline
\end{tabular}


the same temperature, while psycological stress would be expected to be greater during the first than the second procedure. Finally, a certain degree of measurement error is to be expected. Considering the intra- and inter-assay variations of plasma glucose and insulin assays, an estimation of the measurement error would yield a coefficient of variation in insulin sensitivity by the minimal model of approximately 8 to $10 \%$.

In conclusion, these data show that minimal model analysis of FSIGT procedures yields a measure of insulin sensitivity which is reproducible with moderate intra-individual variations when manageable confounding factors are controlled. The FSIGT is also relatively easy to perform and, therefore, potentially useful for the evaluation and monitoring of insulin sensitivity in non-diabetic individuals.

Acknowledgements. We thank Ms. G. Haueter, Ms. T.Marsh, Ms. R. Mosimann, Ms. S. Schwenk, Ms. J. Boden and Ms. A.Zosso for their skilled assistance and the Upjohn Co., Switzerland for kindly furnishing the tolbutamide solution. This work was supported in part by the Swiss National Science Foundation.

\section{References}

1. Himsworth HP (1936) Diabetes mellitus. Its differentiation into insulin-sensitive and insulin-insensitive types. Lancet I: 127-129

2. Himsworth HP, Kerr RB (1939) Insulin-sensitive and insulin-insensitive types of diabetes mellitus. Clin Sci 4: 119-122

3. Andres R, Swerdloff R, Pozefsky T, Coleman D (1966) Manual feedback technique for control of blood glucose concentration. In: Skeggs Jr LT (ed) Automation in Analytical Chemistry. Mediad, New York, pp 486-491

4. De Fronzo RA, Tobin JD, Andres R (1979) Glucose clamp technique: a method for quantifying insulin secretion and resistance. Am J Physiol 237: E214-E223

5. Rizza RA, Mandarino LJ, Gerich JE (1981) Dose-response characteristics for effects of insulin on production and utilization of glucose in man. Am J Physiol 240: E630-E638

6. Bergman RN, Finegood DT, Ader M (1985) Assessment of insulin sensitivity in vivo. Endocrine Rev 6:45-86

7. Shen SW, Reaven GM, Farquhar J (1970) Comparison of impedance to insulin-mediated glucose uptake in normal subjects and in subjects with latent diabetes. J Clin Invest 49:2151-2160

8. Nagulesparan M, Savage PJ, Unger RH, Bennet PH (1979) A simplified method using somatostatin to assess in vivo insulin resistance over a range of obesity. Diabetes 28: 980-984

9. Bergman RN, Ider YZ, Bowden CR, Cobelli C (1979) Quantitative estimation of insulin sensitivity. Am J Physiol 236: E667E677

10. Pacini G, Bergman RN (1986) MINMOD a computer program to calculate insulin sensitivity and pancreatic responsivity from the frequently sampled intravenous glucose tolerance test. Computer Methods Progr Biomed 23: 113-122

11. Beard JC, Bergman RN, Kenneth Ward W, Porte D Jr (1986) The insulin sensitivity index in nondiabetic man. Correlation between clamp derived and IVGTT-derived values. Diabetes 35: 362-369

12. Bergman RN, Prager R, Volund A, Olefsky JM (1987) Equivalence of the insulin sensitivity index in man derived by the minimal model method and the euglycemic glucose clamp. J Clin Invest 79: 790-800

13. Srinivasan SR, Webber LS, Berenson GS (1984) The relationship between very-low-density lipoprotein and measures of carbohydrate metabolism in children with different lipoprotein profiles. Metabolism 33: 760-767
14. Nuttall FQ, Gannon MC, Wald JL, Ahmed M (1985) Plasma glucose and insulin profiles in normal subjects ingesting diets of varying carbohydrate, fat, and protein content. J Am Coll Nutr 4: 437-450

15. Chen M, Bergman RN, Porte Jr D (1988) Insulin resistance and $\beta$-cell dysfunction in aging: the importance of dietary carbohydrate. J Clin Endocrinol Metab 67:951-957

16. Lampman RM, Santinga JT, Savage PJ et al. (1985) Effect of exercise training on glucose tolerance, in vivo insulin sensitivity, lipid and lipoprotein concentrations in middle-aged men with hypertriglyceridemia. Metabolism 34: 205-211

17. Shelmet JJ, Reichard GA, Skutches CL, Hoeldtke RD, Owen OE, Boden G (1988) Ethanol causes acute inhibition of carbohydrate, fat and protein oxidation and insulin resistance. J Clin Invest $81: 1137-1145$

18. Newman WP, Brodows RG (1983) Aspirin causes tissue insensitivity to insulin in normal man. J Clin Endocrinol Metab 57: 1102-1.106

19. Bessey PQ, Brooks DC, Black PR, Aoki TT, Wilmore DW (1983) Epinephrine acutely mediates skeletal muscle insulin resistance. Surgery $94: 172-179$

20. Pollare T, Lithell H, Berne C (1989) A comparison of the effects of hydrochlorothiazide and captopril on glucose and lipid metabolism in patients with hypertension. N Engl J Med 321: 868-873

21. Yang YJ, Youn JH, Bergman RN (1987) Modified protocols improve insulin sensitivity estimation using the minimal model. Am J Physiol 253: E595-E602

22. Manual of laboratory operations. Lipid Research Clinics Program (1974) Lipid and lipoprotein analysis (publication NIH) 75-628 US Department of Health, Education of Welfare

23. Burstein M, Scholnik HR, Morfin R (1970) Rapid methods for the isolation of lipoproteins from human serum by precipitation with polyanions. J Lipid Res 11: 583-595

24. Kolterman OG, Greenfield M, Reaven GM, Saekow M, Olefsky JM (1979) Effect of a high carbohydrate diet on insulin binding to adipocytes and on insulin action in man. Diabetes 28: 731-736

25. Sato Y, Iguchi A, Sakamoto N (1984) Biochemical determination of training effects using insulin clamp technique. Horm Metabol Res 16:483-486

26. Rodnick KJ, Haskell WL, Swislocki ALM, Foley JE, Reaven GM (1987) Improved insulin action in muscle, liver, and adipose tissue in physically trained human subjects. Am J Physiol 253: E489-E495

27. Peiris AN, Müller RA, Smith GA, Struve MF, Kissebah AH (1986) Splanchnic insulin metabolism in obesity. Influence of body fat distribution. J Clin Invest 78: 1648-1657

28. Ferrannini E, Buzzigoli G, Giorico MA et al. (1987) Insulin resistance in essential hypertension. N Engl J Med 317:350-357

29. Pollare $\mathrm{T}$, Lithell $\mathrm{H}$, Berne $\mathrm{C}(1990)$ Insulin resistance is a characteristic feature of primary hypertension independent of obesity. Metabolism 39: 167-174

30. Bar RS, Harrison LC, Muggeo M, Gorden P, Kahn R, Roth J (1979) Regulation of insulin receptors in normal and abnormal physiology in humans. Adv Intern Med 24: 23-52

31. Kahn RC, White MF (1988) The insulin receptor and the molecular mechanism of insulin action. J Clin Invest 82:1151-1156

32. Laakso M, Edelman SV, Brechtel G, Baron AD (1990) Decreased effect of insulin to stimulate skeletal muscle blood flow in obese man. J Clin Invest 85: 1844-1852

Received: 15 January 1991

and in revised form: 2 April 1991

Dr. P. Weidmann

Medizinische Universitaetspoliklinik

Freiburgstrasse 3

CH-3010 Bern

Switzerland 